\title{
How normal body temperature correlate with the cloth's color choice?
}

\begin{abstract}
This study was about the normal body temperature, that how it links with the cloth's color choice. Total 140 subjects took part to complete this study. Body temperature is most significance that makes heat when we need it and release heat when we do not want it. The normal body temperature is $98.6^{\circ} \mathrm{F}$. Clothing is really important for us and most important thing in it is to choose the most likeable color. We measured the normal body temperature by a digital thermometer. t-test was performed and it gave the results that body temperature have no significant relation with the cloth's color choice.
\end{abstract}

Keywords: body temperature, fahrenheit, clothing, fever, heat stroke, hypothermia and cloth's color
Volume 3 Issue I - 2019

\author{
Muhammad Imran Qadir, Maira Naeem \\ Institute of Molecular Biology and Biotechnology Bahauddin \\ Zakariya University Multan, Pakistan
}

\begin{abstract}
Correspondence: Maira Naeem, Institute of Molecular Biology and Biotechnology Bahauddin Zakariya University Multan,
\end{abstract}

Pakistan, Email amnanaeem726@gmail.com

Received: February 08, 2019 | Published: February 26, 2019

\section{Introduction}

Body temperature is the most important thing in our life. It regulates our normal functioning our normal activities of our daily life. The normal body temperature of human is 98.6 degree Fahrenheit. Our environmental conditions our body temperature may change and vary. And if we take our temperature in Celsius scale then it is recommended to be at 37 degree $\mathrm{C}$ under normal conditions. We need our body temperature to make heat in colder areas and to release heat if we are living in too much hotter areas. When we feel too much hotness in our body, our blood vessels expands and they take the extra amount of heat to the skin areas. By this process, we start sweating and when the sweat is evaporated then we feel the coldness. Similarly when we feel too much cold, our blood vessels become thin or narrow, through which there is a reduction of blood flow in the skinny areas. We start to shiver and because of this shivering our muscles shake and they make more heat. One-degree Fahrenheit is equal to 0.6 degree Celsius. What to wear in clothing is the most important question arises in the people. Clothing is most important thing for the humans in order to their bodies and other purposes including for status purposes, being able to show ourselves well good looking and personalized. So most people wear cloths according to their mood and nature. In clothing, there is many varieties like jeans, pent, shirt, coat, shalwar, kammez and many other varieties are present in order to comfort ourselves. Then after choosing the type of cloth, another most important question is to choose the suitable color among cloths. Some choose light colors and some choose darker colors. Darker colors show that they are too much active and bright and dull colors show that they like to be calm in nature and do not like the noisy areas. Purpose of the current study was in accordance with the normal body temperature. ${ }^{1,2}$

\section{Materials and methods}

Total 140 students took part in the present study. The today's study took place in the Bahauddin Zakariya University. These subjects were the students of Bahauddin Zakariya University. Their mean ages are in between 20-22 years.

\section{Measurement of body temperature}

We measured the body temperature by a digital thermometer in current study. We can also measure the body temperature through mouth, which is called oral measurement, by armpit, which is called axillary measurement, by rectum, which is called rectal measurement, and this is the most accurate method for checking the temperature. We checked the temperature by placing the digital thermometer under the armpit for one minute and remove this thermometer when it beeps. And this gives us the accurate body temperature.

\section{Project design}

The questionnaire had been prepared to link the relation between body temperature and cloth's color choice.

\section{Data analysis}

Statistical analysis is done by using the Microsoft excel and Microsoft word. Student's T-Test is also applied in this survey to determine the results.

\section{Results and discussion}

The connection between the body temperatures in Fahrenheit is present in the Figure 1 mentioned below that how the body temperature is related with the cloth's color choice. The present study shows that whether the body temperature is associated with the cloth's color choice or not. This study shows the involvement of 140 subjects in this survey. This study contains the data about mean average and standard deviation and t-test is also applied in this survey to determine the result. Black color shows that the 3 boys and 67 females out of total 140 subjects like this color and have higher body temperature in the subjects. Second option of color which we gave to them is blue color which has 7 boys and 23 females show their interests in liking this color. Third option is white color which have total strength of liking this color is 31 out of total 140 subjects and also the brown color have only one male and eight females which like this color but have least number of body temperature. A questionnaire-based study gives us crucial results in current research work. This survey includes the mean average and standard deviation values of the colors choices on the basis of body temperature and $\mathrm{p}$ value is also mentioned in this context. Black lovers have mean \% and s.d values $95.66 \pm 6.33$, blue color have $96.53 \pm 2.07$, white color have $97.03 \pm 2.22$ and on the last account the brown color which is least liked color amongst the subjects have $97.73 \pm 1.35$ percentages. So naturally black color attracts the most subjects and least liked color is brown. ${ }^{3-10}$ 


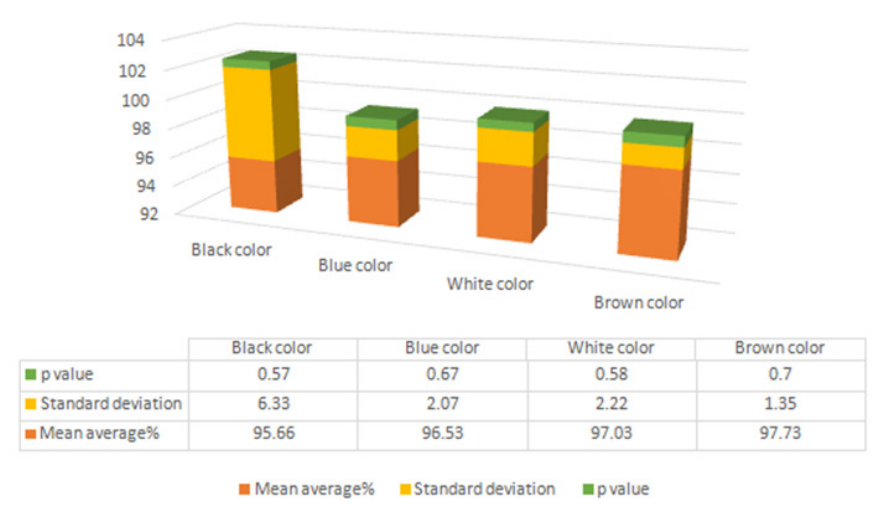

Figure I Linkage of cloth's color with the body temperature.

\section{Conclusion}

It is now proved from the above studies that body temperature have no significant relation to the cloth's color choice.

\section{Acknowledgments}

None.

\section{Conflicts of interest}

The author declares there is no conflicts of interest.

\section{References}

1. Qadir MI, Malik SA. Comparison of alterations in red blood cell count and alterations in hemoglobin concentration in patients suffering from rectal carcinoma undergoing 5-fluorouracil and folic acid therapy. Pharmacologyonline. 2010;3:240-243.

2. Qadir MI, Noor A. Anemias. Rare \& Uncommon Diseases. Cambridge Scholars Publishing. Newcastle, England. 2018; ISBN:978-1-52751807-0.

3. Qadir MI, Javid A. Awareness about Crohn's Disease in biotechnology students. Glo Adv Res J Med Medical Sci. 2018;7(3):062-064.

4. Qadir MI, Saleem A. Awareness about ischemic heart disease in university biotechnology students. Glo Adv Res J Med Medical Sci. 2018;7(3):059-061.

5. Qadir MI, Ishfaq S. Awareness about hypertension in biology students. Int J Mod Pharma Res. 2018;7(2):08-10.

6. Qadir MI, Mehwish. Awareness about psoriasis disease. Int $J$ Mod Pharma Res. 2018;7(2):17-18.

7. Qadir MI, Shahzad R. Awareness about obesity in postgraduate students of biotechnology. Int J Mod Pharma Res. 2018;7(2):14-16.

8. Qadir MI, Rizvi M. Awareness about thalassemia in post graduate students. MOJ Lymphology \& Phlebology. 2018;2(1):14-16.

9. QadirMI, Ghalia BA.Awareness survey about colorectal cancer in students of M. Phil Biotechnology at Bahauddin Zakariya University, Multan, Pakistan. Nov Appro in Can Study. 2018;1(3):NACS.000514.2018.

10. Qadir MI, Saba G. Awareness about intestinal cancer in university student. Nov Appro in Can Study. 2018;1(3):NACS.000515.2018. 